United Nations Educational Scientific and Cultural Organization

and

International Atomic Energy Agency

THE ABDUS SALAM INTERNATIONAL CENTRE FOR THEORETICAL PHYSICS

\title{
SEARCH FOR BACTERIAL WASTE AS A POSSIBLE SIGNATURE OF LIFE ON EUROPA
}

\author{
Aranya B. Bhattacherjee \\ INFM, Dipartimento di Fisica E.Fermi, Università di Pisa, \\ Via Buonarroti 2, I-56127, Pisa, Italy \\ and \\ Department of Physics, A.R.S.D College, University of Delhi, \\ Dhaula Kuan, New Delhi-110021, India ${ }^{1}$ \\ and \\ Julian Chela-Flores \\ Instituto de Estudios Avanzados, Caracas 1015A, Venezuela \\ and \\ The Abdus Salam International Centre for Theoretical Physics, Trieste, Italy.
}

\begin{abstract}
Observations of the icy Jovian moon Europa by the Galileo spacecraft served to stimulate conceptual planning for missions to Europa to search for signs of life in the volcanically- heated ocean presumed to underlie its thick icy surface (Horvath et al, 1997; Chela-Flores, 1998a, b, 2003; Greenberg, 2002, Pappalardo et al, 1999). Liquid water is thought to be an essential ingredient for life, so the existence of a second water ocean in the solar system would be of paramount importance in any search for life beyond earth. In-situ measurements will be needed to directly explore the Europan ocean. The wide range of thermal and pressure environments expected on Europa provide a considerable challenge in designing an instrument package.
\end{abstract}

MIRAMARE - TRIESTE

July 2004

\footnotetext{
${ }^{1}$ Permanent address.
} 


\section{Introduction: The Presence of Bacterial Waste and its Consequence}

Of particular interest to the scientific community is the possible existence of extraterrestrial biological activity due to the presence of liquid water under the icy surface. This search is motivated by analogy with anaerobic life found in abundance in under sea volcanic vents on Earth (McCollom 1999; Pappalardo et al, 1999) and the dry valley lakes of Antarctica. If Europa does indeed have a liquid water ocean beneath the outer ice crust as a result of interior volcanic heating, then it is possible that hydrothermal vents located on the seafloor may provide the necessary conditions for simple ecosystems to exist. The water ejected from the hydrothermal vents is typically rich in sulfur and other minerals. Bacteria present in the water extract all nutrients directly from the sulfur via chemosynthesis, making sunlight and oxygen unnecessary. Geochemical models have been proposed to explore the possibility that lithoautotropic methanogenesis $\left(\mathrm{CO}_{2}+4 \mathrm{H}_{2}=\mathrm{CH}_{4}+2 \mathrm{H}_{2} \mathrm{O}\right)$ could be a source of metabolically useful chemical energy for the production of biomass at putative Europan hydrothermal systems (McCollom, 1999; Delitsky and Lane, 1997). In the absence of oxygen, anaerobic decomposition takes place in these hydrothermal vents. As a result of putrefactive breakdown of organic material (proteins), some elements are produced, such as hydrogen sulfide, methane, ammonia, and mercaptans, which are thiols/thio alcohols (RS-H, R-paraffinic, aromatic or cyclopraffine group). The sulfur in mercaptans found in bacteria ultimately derives from sulfate $\left(-\mathrm{SO}_{4}{ }^{2-}\right)$, which is reduced in the cell. In bacteria that utilize sulfate as a source of sulfur, several steps in the reduction process eventually lead to hydrogen sulfide $\left(\mathrm{H}_{2} \mathrm{~S}\right)$ which is a direct precursor of the amino acid cysteine which is a thiol! The original source of sulphur on the Europan surface may be either: (a) ions implanted from the Jovian plasma, or alternatively, (b) much of the sulphurous material may be endogenic. The first possibility (a) has the difficulty that implantation would be expected to produce a more uniform surface distribution (Carlson et al, 1999). On the other hand, sulphurous material on Europa's surface may have been formed internally and over geologic time it could have been emplaced onto the surface either geologically, or as we argue in this paper by the accumulated effect of biogenic processing over geologic time. Interestingly, evidence has been provided for the presence of mercaptans on the surface of Europa (McCord et al, 1998), using reflectance spectra returned by the Galileo near infrared mapping spectrometer (NIMS) experiment. They found absorption in the $3.88 \mu \mathrm{m}$, attributed to $\mathrm{S}-\mathrm{H}$ bond of mercaptans. A major scientific question to be answered about the possible existence of life is: If biological process such as methanogenesis and putrefaction are at work then how do they affect observable or measurable quantities? What would be the best way to detect these organisms? In order to answer such questions, lander missions would be needed since it seems unlikely that remote sensing techniques such as NIMS alone would be sufficient. An ideal approach to detect the presence of life would be to drop penetrating probes and an in situ vehicle, which would carry a chemical/physical laboratory (CPL). The in situ CPL will perform chemical and physical analysis of ice and ocean water to obtain information on the chemical constituents of the ice. Instruments required for these analyses would include UVspectrometer, high frequency ultrasonic analyzers, chemical analyzer to look directly for bacterial metabolic wastes or indirect effect of these waste products on the icy surface or the water beneath. Interestingly, the use of fermentative products (organics and carbon dioxide) as metabolic signatures on Europa has been suggested (Prieur, 2002).

\section{What Kind of Solute-Solvent Interactions We Should Expect on Europa's Surface?}

The presence of various bacterial excreta is expected to perturb the normal water lattice as $\left(\mathrm{H}_{2} \mathrm{O}\right)_{\text {liquid }}\left(\mathrm{H}_{2} \mathrm{O}\right)_{\text {quasi-lattice. }}$ Release of these excreta over a prolonged period of time would 
certainly change the various physical properties of the icy layer and that of the water that lies beneath. The perturbations would be reflected in the various physical properties measured such as the viscosity, ultrasonic velocity, ultrasonic absorption coefficient, UV absorption spectra etc. UV absorption spectra are quite ideal for monitoring the formation/breaking of hydrogen bonds. An enthalpy change of $5-7 \mathrm{kcal} / \mathrm{mole}$ is expected during the formation/breaking of hydrogen bonds. The most likely hydrogen bond that may be formed is between the hydrogen of iodole chromophore and water molecule. The iodole chromophore may act as a proton donor in the hydrogen bonding. Low molecular weight and high functionality of water plays a significant role in biological processes. Water can be assumed to be a two-state system (Pethrick, 1982). Each molecule is joined to its nearest neighbors with four links. On the surface of these clusters exist molecules joined by less than the maximum number and may be considered to be in the process of either forming or breaking the cluster. The total can be divided into two regions, an open low density arrangement where the molecules are extensively hydrogen bonded and a high density region where the molecules are non-bonded. The equilibrium may be described as: $\left(\mathrm{H}_{2} \mathrm{O}\right)_{\text {liquid }}$ (bound) $n$ $\left(\mathrm{H}_{2} \mathrm{O}\right)$ (free monomeric). Solute molecules (bacterial waste) which have the ability to form hydrogen bonds will attack the low density region and may act as acceptors and compete with the protons for the lone pair of electrons. The net result of such interaction is the disruption of the low density region and the equilibrium shifts towards the non-bonded form with a consequent increase in the density. Such a transition will change the freezing point of water and can be measured using high frequency ultrasonic transducers. Increase in solute concentration (bacterial waste) over a prolonged period of time is expected to produce an enthalpy change of 1-2 kcal/mole. This will be reflected as a red shift in some standard UV spectral lines. This happens because of the "Franck-Condon's "strain and the "Polarization shift" (Chaudhury et al, 1994). The importance of experiments to detect bacterial wastes including mercaptans, that NIMS has demonstrated to be present on the Europan surface must be realized because non-living sources of mercaptans are difficult to anticipate.

\section{Discussion and Conclusions}

The detection and characterization of any bacterial excreta is an integral part of our search for evidence of life on Europa. In order to achieve this goal, it will be necessary to embark on an extensive survey of the surface of Europa using lander missions. Clearly an ideal approach to obtaining information on the composition of the European "ocean" is to sample the surface material which is thought to have originated at depth and become distributed on the surface by eruption like processes.

Any point on the surface of Europa which exhibits properties typical of contamination by bacterial waste should serve as a window to the underlying ocean. Before embarking upon any ambitious project, it would be helpful if we could test this proposal in the laboratory by mimicking the surface of Europa. This could be done by allowing for bacteria to grow for a prolonged period in an artificial pond and then freezing the water. Subsequently one can measure the various physical and chemical properties on the surface of this pond. This will help to understand what we should expect on the surface of Europa. However, in this context we should point out that such an experiment is probably mimicked by nature in the dry valley lakes of southern Victoria Land of Antarctica (Doran et al, 1994; Parker et al, 1982). These lakes lie in an ice-free area of just under $5000 \mathrm{~km}^{2}$. This area contains more than 20 permanent lakes, which are warm environments containing liquid water that may reach room temperature under their iced surface of 4-6 m, while the outside temperature remains well below zero degrees Celsius. In the dry valley lakes there are abundant microorganisms underneath their iced surface. The estimated annual S removal is $104 \mathrm{~kg}$ in Lake Chad [cf., 
Table 5 in (Parker et al, 1982)]. At any given time an important characteristic of the anaerobic prostrate cyanobacterial mats of, for instance Lakes Fryxell and Hoare, is their appearance as black mats, coarse and with a distinct $\mathrm{H}_{2} \mathrm{~S}$ odor (Doran et al, 1994). Thus, at any given moment endogenic sulphur and other elements are to be found on the iced surface of, for instance, Lake Chad. To the best of our knowledge, there is no information on the presence of mercaptans in the dry valley lakes of Antarctica. Further investigations are required to search for mercaptans (or other bacterial wastes) in these dry valley lakes. There is, therefore, a suggestive analogy between the chemical composition of the surface of the dry valley lakes with the presence of sulfur compounds (such as mercaptans) on the iced surface of Europa.

\section{Acknowledgements.}

A. Bhattacherjee acknowledges support by the Abdus Salam International Centre for Theoretical Physics, Trieste, Italy under the ICTP-TRIL fellowship scheme.

\section{References}

Carlson, R. W., Johnson, R. E. and Anderson, M. S. (1999) Sulfuric acid on Europa and the radiolytic sulfur cycle, Science, Vol. 286, pp. 97-99.

Chaudhury, K., Bhattacherjee, A., Bajaj, M.M. and Jain, D.C. (1994) An analysis of 5-(pHydroxyphenyl)-5-phenylhydantoin induced perturbations in the $200-400 \mathrm{~nm}$ region, Revue Roumaine de Chimie, Vol. 39, pp.1091-1098.

Chela-Flores, J. (1998a) Europa: A potential source of parallel evolution for microorganisms, In: Instruments, Methods and Missions for Astrobiology. The International Society for Optical Engineering, Bellingham, Washington USA (R.B. Hoover, ed.), Proc. SPIE, Vol. 3441, pp. 55-66; http://www.ictp.trieste.it/ chelaf/ss4.html

Chela-Flores, J. (1998b) A search for extraterrestrial eukaryotes, Physical and Biochemical Aspects of Exobiology, Origins Life Evol. Biosphere, Vol. 28, 583-596; http://www.ictp.trieste.it/ chelaf/searching_for_extraterr.html

Chela-Flores, J. (2003). Testing Evolutionary Convergence on Europa. International Journal of Astrobiology

(Cambridge University Press), in press. http://www.ictp.trieste.it/ chelaf/ss 13.html

Delitsky Mona L. and Lane, Arthur L. (1997) Chemical schemes for surface modification of icy satellites: A road map, Jour. Geochem. Res., Vol. 102, No. E7, pp. 16,385

Delitsky, L. and Lane, A. L. (1998) Ice chemistry in Galilean satellites Jour. Geophys. Res. Vol. 103, pp. 31,391 - 31,403.

Doran, P.T., Wharton, Jr., R.A. and Berry, Lyons, W. (1994) Paleolimnology of the McMurdo Dry Valleys, Antarctica, J. Paleolimnology 10, pp. 85-114.

Greenberg, R. (2002), Tides and the biosphere of Europa, American Scientist, Vol. 90, pp.4855.

Horvath, J. Carsey, F., Cutts, J. Jones, J. Johnson, E.. Landry, B., Lane, L., Lynch, G., ChelaFlores, J., Jeng, T-W. and Bradley, A. (1997) Searching for ice and ocean biogenic activity on Europa and Earth, Instruments, Methods and Missions for Investigation of Extraterrestrial Microorganisms, (R.B. Hoover, ed.), SPIE, Vol. 3111, pp. 490-500; http://www.ictp.trieste.it/ chelaf/searching_for_ice.html

McCollom, T. M. (1999), Methanogenesis as a potential source of chemical energy for primary biomass production by autotrophic organisms in hydrothermal systems on Europa, Jour. Geochem. Res. Vol.104, No. E12, pp.30, 729-30742. 
McCord, T.B., Hansen, G.B., Clark, R.N., Martin, P.D., Hibbitts, C.A., Fanale, F.P., Granahan, J.C., Segura, NM., Matson, D.L., Johnson, T.V., Carlson, R.W., Smythe, W.D., Danielson, G.E., and the NIMS Team (1998) Non-water-ice constituents in the surface material of the icy Galilean satellites from the Galileo near-infrared mapping spectrometer investigation, Jour. Geophys. Res. Vol. 103, No. E4, pp. 8603-8626.

Pappalardo, Robert T. James W. Head and Ronald Greeley (1999) The hidden ocean of Europa, Scientific American, pp. 34-43.

Parker, B.C., Simmons, Jr., G.M., Wharton, Jr., R.A. Seaburg, K.G. and Love, F. Gordon (1982) Removal of organic and inorganic matter from Antarctic lakes by aerial escape of bluegreen algal mats, J. Phycol. Vol. 18, pp. 72-78.

Prieur, D. (2002) Life detection on Europa: Metabolic signatures, Europa Focus Group Workshop 3, Arizona, USA, p. 41.

Pethrick, R.A. (1982) Molecular Interactions Vol.3, In: H. Ratajczak and W.J. Orville- (eds.) Thomas, John Wiley and Sons, New York. 